\title{
SWAT BASED ASSESSMENT AND PREDICTION OF CLIMATE CHANGE AND ITS IMPACT IN THENPENNAI SUB-BASIN OF SOUTH INDIA
}

\author{
K. Nivedita Priyadarshini ${ }^{1}$, S. Abdul Rahaman ${ }^{2}$, , S. NitheshNirmal ${ }^{3}$, R. Jegankumar ${ }^{4}$, P.Masilamani $^{5}$ \\ ${ }^{1}$ M.Tech Geoinformatics, Dept. of Geography, Bharathidasan University, Tiruchirappalli, Tamil Nadu- nivi.darshini@yahoo.com \\ ${ }^{2}$ Research Fellow, Dept. of Geography, Bharathidasan University, Tiruchirappalli, Tamil Nadu - abdulatgeo@ gmail.com \\ ${ }^{3}$ M.Sc. Geography, Dept. of Geography, Bharathidasan University, Tiruchirappalli, Tamil Nadu, - nirmalgsarath@ gmail.com \\ ${ }^{4}$ Assistant Professor and head, Dept. of Geography, Bharathidasan University, Tiruchirappalli, Tamil Nadu \\ ${ }^{5}$ Assistant Professor, Dept. of Geography, Bharathidasan University, Tiruchirappalli, Tamil Nadu
}

\section{Commission V, SS: Atmosphere, Ocean, Weather and Climate}

KEY WORDS: SWAT model, climate change, precipitation, temperature, policy making, adaptation strategies.

\begin{abstract}
:
Climate change impacts on watershed ecosystems and hydrologic processes are complex. The key significant parameters responsible for balancing the watershed ecosystems are temperature and rainfall. Though these parameters are uncertain, they play a prime role in the projections of dimensional climate change studies. The impact of climate change is more dependent on temperature and precipitation which contributes at a larger magnitude for characterising global warming issues. This paper aims to forecast the variations of temperature and precipitation during the period of 2020-2050 for the northern part of Thenpennar sub basin. This study is modelled using SWAT (Soil and Water Assessment Tool) - a scale model developed to predict the impact of changes that occurs in land, soil and water over a period of time. This study is validated using the base period from 1980-2000 which shows the distribution of rainfall and temperature among 38 watersheds. The results from this study show that there is a decrease in the rainfall for a maximum of about $20 \%$ in the month of December during the predicted period of 2020 and 2050. This study assesses the possible adverse impact of climate change on temperature and precipitation of Thenpennai sub-basin. This kind of predictions will help the government agencies, rulers and decision makers in policy making and implementing the adaptation strategies for the changing climatic conditions.
\end{abstract}

*Corresponding author: S. Abdul Rahaman

Email: abdultgeo@gmail.com 


\section{INRODUCTION}

\subsection{Consequences of a warming globe}

Over the last century, global average temperature has increased by more than $1^{\circ} \mathrm{F}\left(0.7^{\circ} \mathrm{C}\right)$ and much substantial scientific research had proved the increase in temperature of the globe since 2001. This warming causes an adverse effect upon climate thus changing the rainfall patterns resulting in drought, famine or severe storms (Union of Concerned Scientists, 2011). Global climate is projected to change over centuries which are primarily due to trapping of green house gases. According to the Intergovernmental Panel on Climate Change (IPCC, 2013), the scientists forecast a temperature rise of 2.5 to 10 degrees Fahrenheit over the next century.

\subsection{Impact of climate change on watershed}

Climate-induced increase in surface temperatures can impact hydrologic processes of a watershed system (Marshall et al., 2008). This may include both physical factors such as temperature, rainfall, runoff, sediment yield etc, and chemical factors which quantify nitrates and phosphates discharged from each sub watersheds. Due to adverse climate change there is a critical impact in increasing frequency and magnitude of both floods and droughts. Hence a proper management of watershed is required to reduce risk and vulnerability from these impacts (Schneider, 2014).This paper attempts to predict the monthly variation of temperature and rainfall from the year 2020-2050. For this, a sample dataset is used for validation and calibration which is signified as the 'base period' from the year 1980-2000. The result shows the average of monthly precipitation and temperature acquired using SWAT.

\section{REVIEW OF LITERATURE}

Hydrological modeling of the watershed using the SWAT (Soil and Water Assessment Tool) model was developed by the United State's Department of Agriculture (USDA), which is a conceptual model, deterministic and semi-spatial, that takes into consideration several parameters (soil types, land use, topography etc) (Bouslihim et al., 2016). The SWAT model has been implemented with the aim of predicting the impact of land management activities with regard to water, sedimentation, and chemical-agricultural agents in the presence of a variety of soil, land cover, and management conditions during long period. Each sub watershed is divided into a number of HRU (Hydrologic Response Units). The hydrologic response unit is the smallest spatial unit of the model, and the standard HRU definition approach lumps all similar land uses, soils, and slopes within a sub-basin based upon user-defined thresholds. This standard method provides an efficient way to discretize large watersheds where simulation at the field scale may not be computationally feasible (Kalcic et al., 2015).The sub-basin components can be categorized into the following components: hydrology, weather, erosion, and sedimentation, soil temperature, plant growth, nutrients, pesticides and land management (Zahabiyoun et al., 2013). Model setup was accomplished using the spatial data and gridded climate datasets. Model calibration is the process of selecting the most suitable parameters for running a model to a given set of local conditions to reduce prediction uncertainty. Model validation is the process of demonstrating that a given model is capable of making sufficiently accurate predictions based on the purpose of the project (Dlamini et al., 2017). The monthly simulation scenarios were forecasted and analyzed for all HRU's (ALHeetimi et al., 2016). Useful model outputs are ET, surface runoff, peak flow, sediment loading, nutrient loading, ground water movement (infiltrated water going to aquifer), soil water content, lateral (subsurface) flow, infiltration, minimum temperature, maximum temperature, precipitation etc. (Kuhn, 2014). SWAT requires various input data for simulation of watershed. The data required are Digital Elevation Model (DEM), Land use/Land cover, soil cover, precipitation, temperature, relative humidity, wind speed, solar radiation. The various steps involved in the software are watershed delineation, HRU (Hydrological response Unit) analysis, and Write input tables, edit input data and SWAT simulation. Once it is over software will begin the execution and will print the output file. This output file will be used to plot the graphs and maps (Renganathan et al., 2015). Root-Mean-Square Error (RMSE) is a frequently used measure of the differences between values actually observed and the values predicted by a model. RMSE has been calculated to check the applicability of the model (Panhalkar, 2014).

\section{STUDY AREA AND DATASETS}

\subsection{Study Area}

In this study, Thenpennai sub-basin is selected as the study area which lies between $77^{\circ} 33^{\prime} \mathrm{E}$ to $79^{\circ} 47^{\prime} \mathrm{E}$ longitude and $11^{\circ} 45^{\prime} \mathrm{N}$ to $13^{\circ} 30^{\prime} \mathrm{N}$ latitude (Figure 1). The sub-basin covers an area of about $9319.69 \mathrm{~km}^{2}$. Thenpennai sub-basin lies in the northern part of the Ponnaiyar or the Thenpennar which is the second largest interstate river basin flowing in the states of Tamil Nadu, Karnataka and Andhra Pradesh. Agriculture is the main occupation of the people in this region. The river originates from the south eastern side of Chennakesma hills and north western side of Nandi hills or Nandidurg in the Chikkaballapur district of Karnataka. It drains about $85 \mathrm{Km}$ within Karnataka, to the north of Bengaluru. It enters Tamil Nadu at Pagalur in Hosur taluk of Krishnagiri district. It covers an area of $400 \mathrm{Km}$ from its origin till it empties into Bay of Bengal at Cuddalore district of Tamil Nadu.

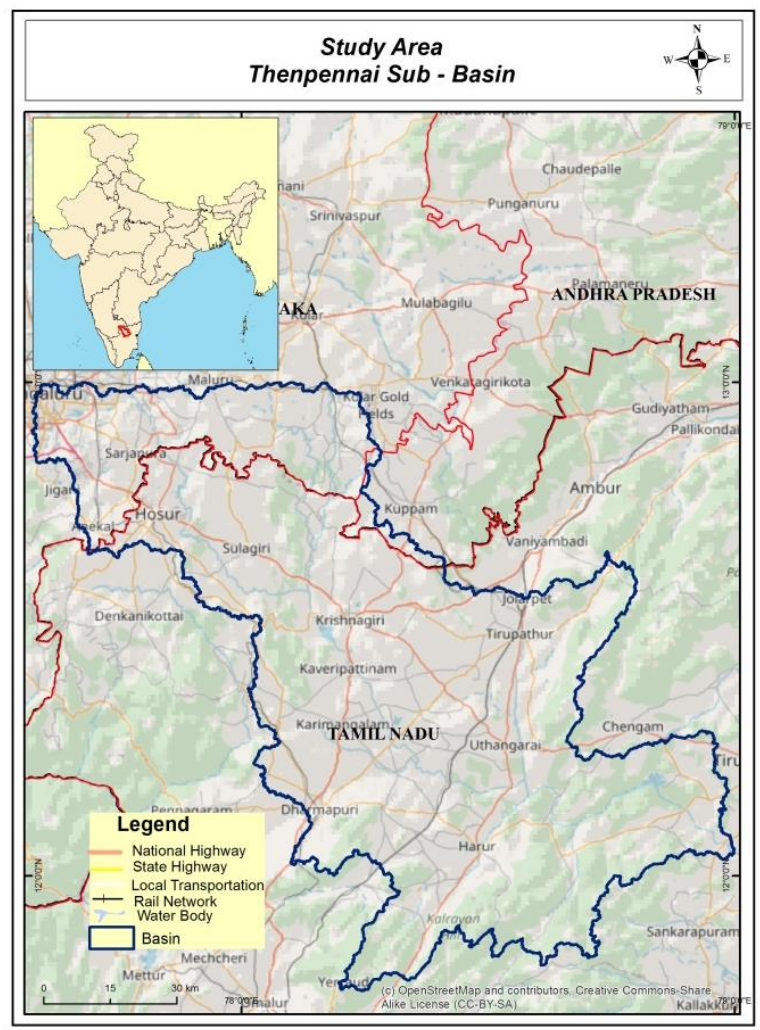


Figure 1. Study area

\subsection{Datasets Used}

For the monthly simulation of precipitation and temperature several parameters were given as input in Arc SWAT. Some of them include the landuse/landcover, soil type, slope and a complete weather database comprising data like - rainfall, temperature, solar radiation, relative humidity and wind speed. The datasets were both in the form of layers and databases. The source DEM that provides the elevation information was used for delineating the basin and was acquired from ASTER DEM of $30 \mathrm{~m}$ resolution. The landuse/landcover was taken as a raster dataset from GLCC (Global Land Cover Characterization). The corresponding soil cover data which matches to the study area was from FAO Soils portal (Food and Agricultural Organisation). Weather database from CFSR (Climate Forecast System Reanalysis) of $\sim 38 \mathrm{~km}$ atmospheric resolution were imported.

\section{METHODOLOGY}

\subsection{Watershed delineation}

The projected source DEM was the input to delineate the subbasin automatically in Arc SWAT. For the given input DEM, stream definition parameters such as, flow direction and accumulation were calculated. The total area after stream definition was $18639.377 \mathrm{Ha}$ and numbers of cells were 196483. The stream definition was followed by the stream network process where the outlets were defined manually by adding point source to each sub-basin. The sub-basin was then delineated by selecting the watershed outlets on a whole. In this study, the Thenpennai sub-basin was divided into 38 watersheds shown in Figure 2. Each sub basin's respective area covered, length, reach, width, depth etc. were estimated by calculating the sub basin parameters.

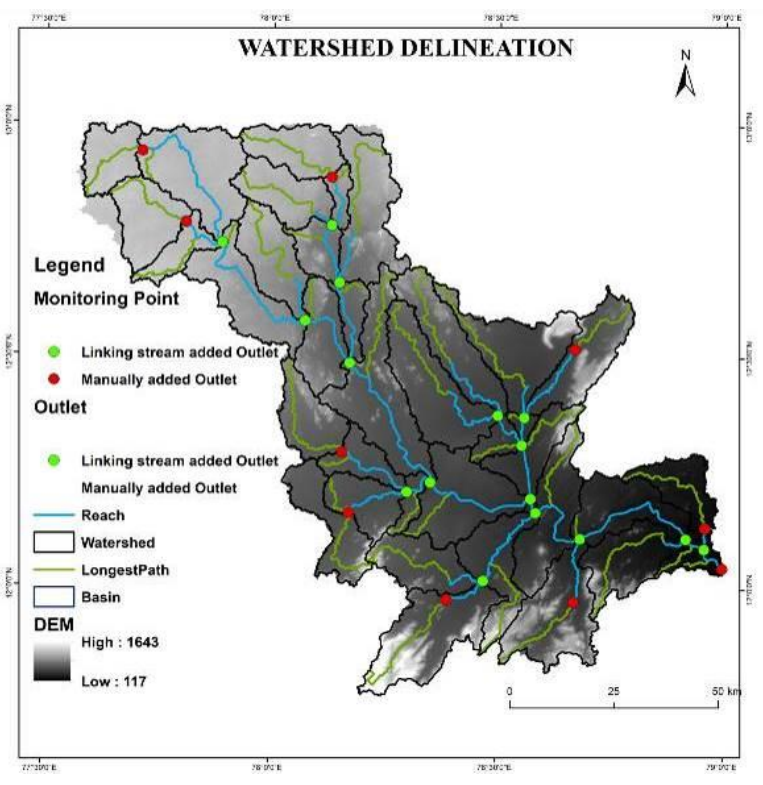

Figure 2. Watershed Delineation

The workflow of the SWAT process has been given in the Figure 3.

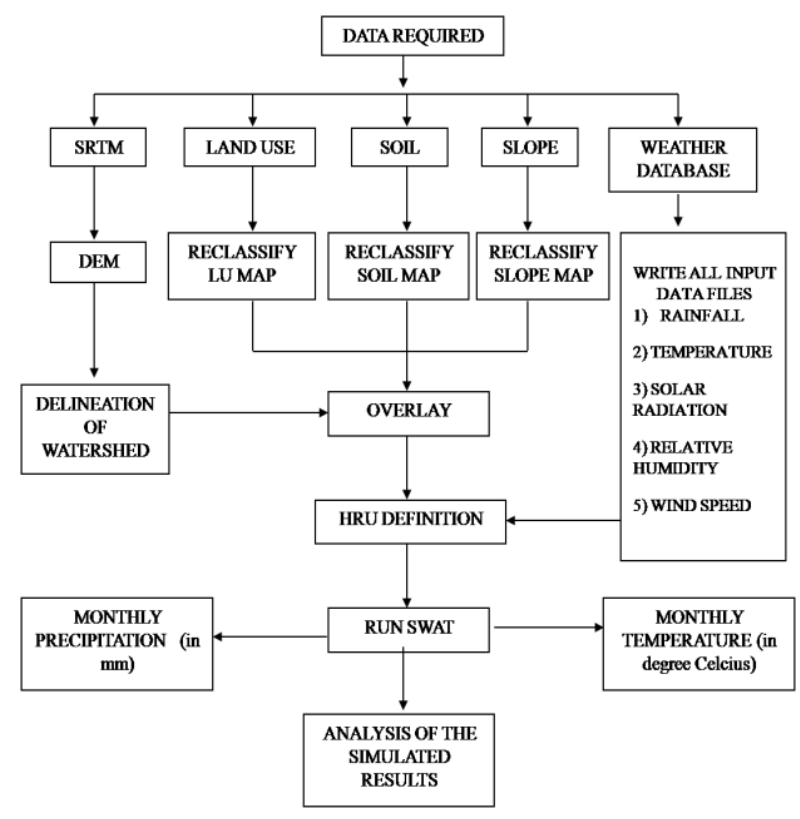

Figure 3. Workflow of SWAT model

\subsection{Landuse/Soil/Slope Definition}

The work flow of the SWAT model is given below where, the raw input requirements are:

- Landuse/landcover - The physical land type of the study area is defined by importing the LU/LC data. The required area was extracted using the sub-basin boundary and imported as raster file in land use definition. Figure 4. shows the imported raster data containing values and its corresponding classification as per the GLCC dataset. The landuse/landcover raster was then reclassified according to the LULC USGS classes (SWAT- Land use classes). The Lookup table for LU/LC of the Thenpennai sub-basin is given in the Table 1 .

$\bullet$

\begin{tabular}{|c|c|c|}
\hline $\begin{array}{c}\text { Lookup } \\
\text { Table } \\
\text { values }\end{array}$ & GLCC classification & $\begin{array}{c}\text { SWAT- } \\
\text { landuse } \\
\text { classes }\end{array}$ \\
\hline 1 & Tropical evergreen & AGRL \\
\hline 5 & Tropical semi-evergreen & HAY \\
\hline 8 & Tropical moist deciduous & FRSE \\
\hline 9 & Tropical dry deciduous & WELT \\
\hline 12 & Degraded forest & PAST \\
\hline 15 & $\begin{array}{c}\text { Thorn forest/ scrub } \\
\text { (southern) }\end{array}$ & RNGE \\
\hline 32 & $\begin{array}{c}\text { Irrigated intensive } \\
\text { agriculture }\end{array}$ & OATS \\
\hline 33 & Irrigated agriculture & RICE \\
\hline 35 & Rainfed agriculture & TIMO \\
\hline 45 & Dry crops & RYER \\
\hline
\end{tabular}

Table 1. GLCC LU/LC Classification

- $\quad$ Soil - The FAO soil type was initially obtained as layer file and converted to raster format to give as input for defining the soil cover shown in Figure 5. Soil cover data finally was reclassified based on user defined FAO soil type (SWAT- Soil Class). Hydrographic Soil Group (HSG) of 


\begin{tabular}{|c|c|c|c|}
\hline Row_id & HSG & Soil order & $\begin{array}{c}\text { SWAT soil } \\
\text { classes }\end{array}$ \\
\hline 0 & Misc & Miscellaneous & RAYNHAM \\
\hline 1 & R.F & Reserve Forest & SHEEPSCOT \\
\hline 2 & C & Inceptisols & DEERFIELD \\
\hline 3 & A & Alfisols & WALLKILL \\
\hline 4 & B & Entisols & ELDRIDGE \\
\hline 5 & D & Vertisols & BIRDSALL \\
\hline
\end{tabular}

Table 2. Hydrographic Soil Group (HSG)

- $\quad$ Slope - It is an important factor that determines water, nutrients and sediment movements. The number of slope classes were defined 2 ranging between $0-3$ (lower limit) and 3-9999 (upper limit) shown in Figure 6 . The defined slope was then reclassified.

\subsection{HRU Analysis}

The three input parameters were overlaid to create the HRU feature classes. A layer is generated showing the total of 105 HRU for 38 sub basins that are shown in Figure 7, with 20\% threshold for each of the landuse/soil/slope. The main source for determining climate factors were obtained from landuse/soil/slope defined HRU's in conjunction with weather database. The outcome of importing the database provides a report in which each of $105 \mathrm{HRU}$ are grouped based on the existing landuse pattern and soil type. The climate change in one way is dependent on the landuse, soil and slope since a whole of measurement is done for each watershed in the subbasin. Amount of precipitation and temperature are direct sources from observed data that are influencing the HRU.

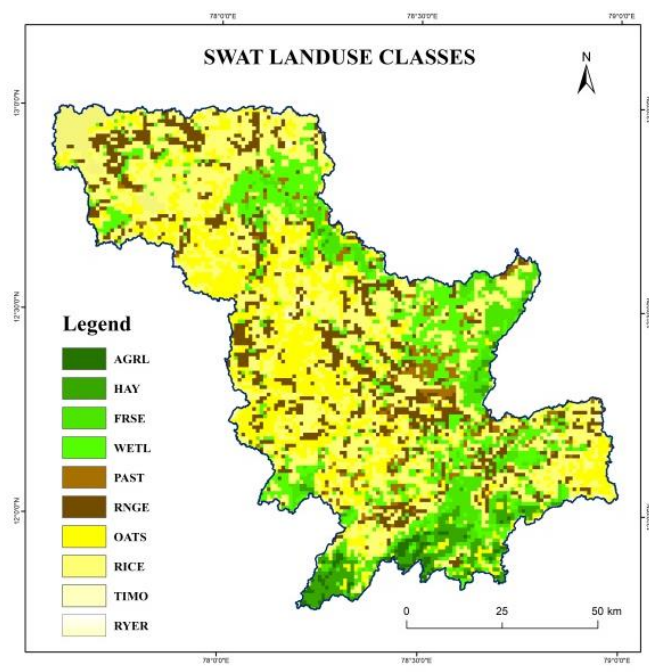

Figure 4. SWAT LU/LC classes

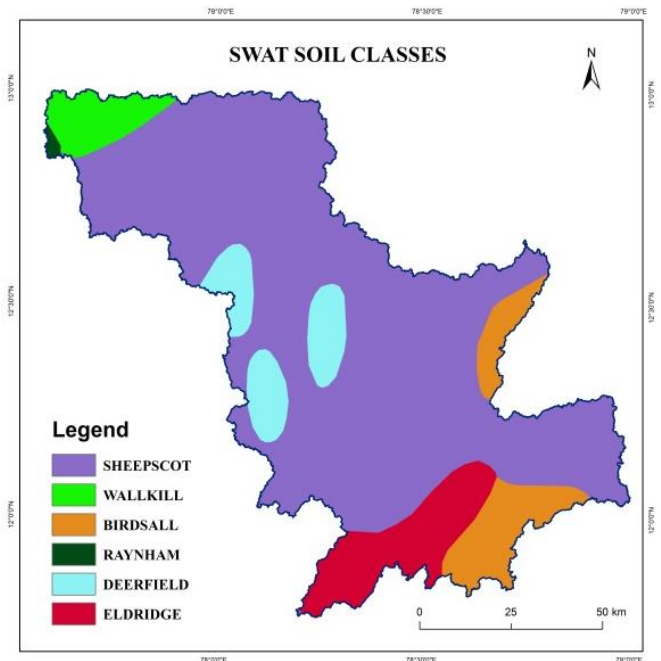

Figure 5. SWAT Soil classes

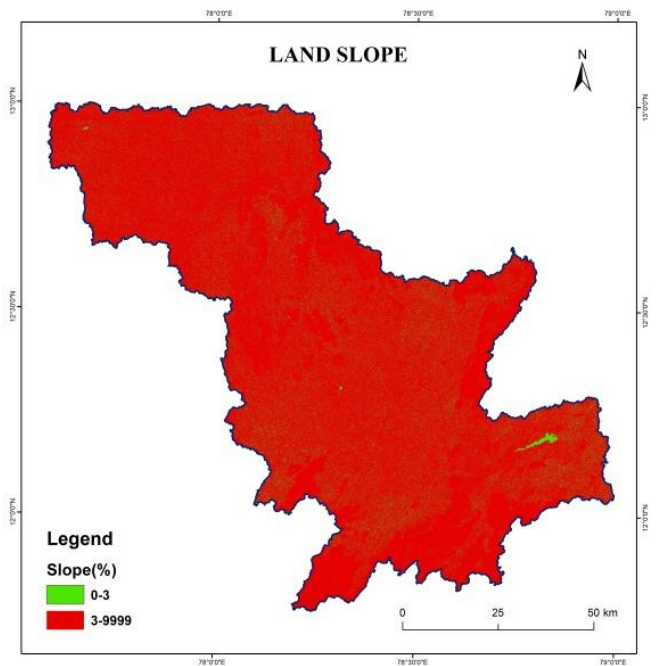

Figure 6. SWAT Land slope

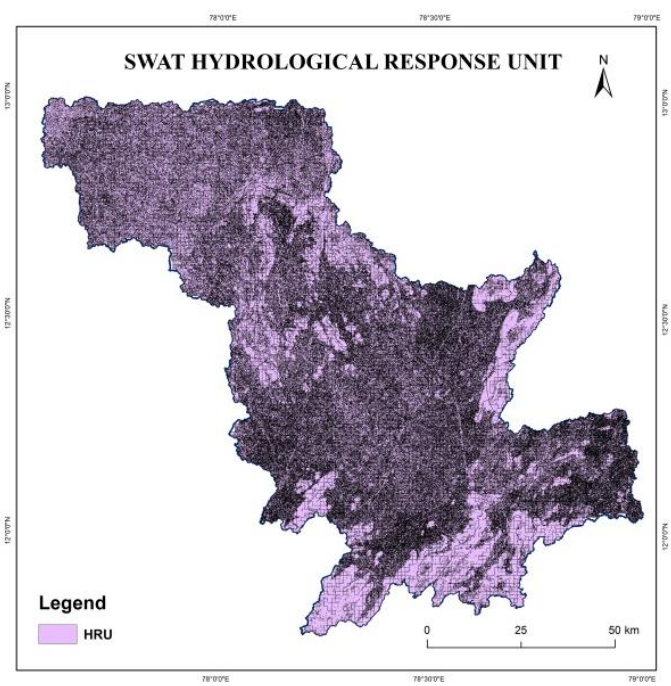

Figure 7. Hydrologic Response Unit

\subsection{Weather database}

Meteorological data consisting of rainfall ( $\mathrm{mm})$, maximum and minimum temperature $\left({ }^{\circ} \mathrm{C}\right)$, wind speed $(\mathrm{km} / \mathrm{hr})$, relative humidity (\%), solar radiation $\left(\mathrm{cal} / \mathrm{cm}^{2}\right)$ obtained from the CFSR 
world database is imported into Arc SWAT weather database. These values according to the respective latitude, longitude and elevation of the study area were analysed by the software and the input files were written automatically.

\subsection{Model Calibration}

For preliminary testing, model calibration is an essential process (Panhalkar, 2014). Calibration and validation in general, is done to ensure that the parameters used represent the study area (Zahabiyoun et al., 2013).The model was calibrated for analysing the temperature and precipitation using the observed data. This phase is considered as the training phase in which the first 20 years (1980-2000) of data were used for priming the model. The datasets were calibrated and validated in order to obtain successful hydrological simulation results. Thus, simulated results showing better correlations can be used for further studies.

\section{RESULTS AND DISCUSSION}

\subsection{SWAT Simulation}

The finalized SWAT input layers and databases are setup and SWAT model was run to simulate results. Based on the observed results, SWAT simulation for a period of 30 years from 2020-2050 were carried out.

\subsection{Change evaluation of simulated results}

Temperature and precipitation always have a direct impact on phenomena like water resource, climate, agriculture etc. The simulations generated were represented statistically using graphs. The Figure 8. Shows the variation of for the observed (1980-2000) and predicted years (2020-2050).

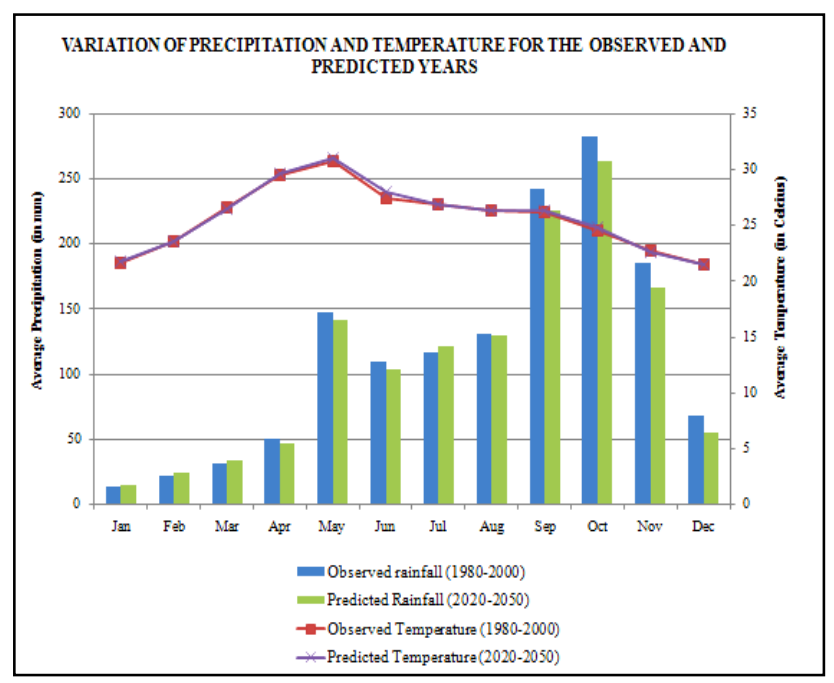

Figure 8. precipitation and temperature for observed (19802000) and predicted years (2020-2050).

The results were evaluated and analysed which depicts distribution of rainfall varied at a certain amount from 20202050 corresponding to the base period 1980-2000 and showing not much difference in temperature. The percentage changes in the average monthly rainfall of 2020-2050 when compared with the base period is shown in the Figure 9.

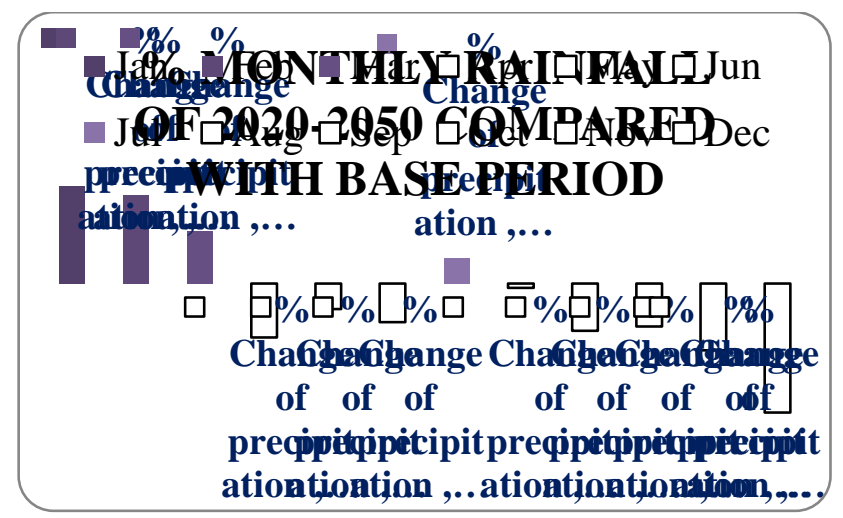

Figure 9. Precentage monthly rainfall of 2020-2050 compared with base period (1980-2000).

From the results it is evident that rainfall is seen mostly decreasing during the months of April, May, June, August, September, October, November and December. The maximum decrease in the amount in the rainfall is seen in the month of December while increasing trend of rainfall is seen in the months of January, February and March. This change in the rainfall pattern depicts the shift in the climate from the present situation. During the month of January, there is a $15 \%$ increase in the average rainfall, followed by $13 \%$ in February, $8 \%$ in march and an increase of $4 \%$ during the month of March whereas there is a decrease in the rainfall for about $-8 \%$ in April, $-4 \%$ in May, $-6 \%$ in June, $-1 \%$ in August, $-7 \%$ in September and October and $-10 \%$ and $-20 \%$ during November and December. From the results, it is evident that during the summer months (April and May), there will be an increase in the temperature with decrease in the amount of rainfall. Except in July all the other months of south-west monsoon receives very less rainfall in the predicted years whereas the month of July receives a rainfall more than that of the base year. A decrease of rainfall is seen in the predicted years during the months (Oct-Dec) of north-east monsoon. During the winter season (Jan-Feb) there is an increase in the rainfall amount. The temperature of the study area does not deviate that much as like in the case of precipitation.

\section{CONCLUSION}

The prediction of rainfall and temperature of a watershed in a long run is very important in adapting the strategies to reduce the impacts of the climate change. This study based on SWAT model clearly notifies that the climate of Thenpennai sub-basin will experience significant changes in the near future. The comparison between the observed and the stimulated climatic variables during 2020-2050 shows that during the summer months, there will be an increase in temperature for about 0.5 $1^{\circ} \mathrm{C}$ whereas precipitation will witness a change of -20 and +20 respectively. There is a decrease of rainfall especially during the months of south-west monsoon and north-east monsoon which impose a serious threat to the rainfed agriculture of the Thenpennai sub-basin. The government agencies and rulers should take the preventive measures for adapting the changing climate.

\section{REFERENCES}

Al-Heetimi, Oday \& A. A., Wissam \& Jaber, Jabbar.(2016). "Flood Forecasting in Upper Zab River Using SWAT Hydrological Model". Kerbala University, 14, pp.133-144 
Bouslihim, Y., Kacimi, I., Brirhet, H., Khatati, M., Rochdi, A., Pazza, N. E., et al. (2016). "Hydrologic Modeling Using SWAT and GIS,Application to Subwatershed Bab-Merzouka(Sebou, Morocco)". Journal of Geographic Information System ,08, pp. 20-27.

Dlamini, N. S., Kamal, M. R., Soom, M. A., Mohd, M. S., Abdullah, A. F., \& Hin, L. S. (2017). "Modeling Potential Impacts of Climate Change on Streamflow Using Projections of the 5th Assessment Report for the Bernam River Basin, Malaysia”. MDPI , 9, 226.

Kalcic, M. M., Chaubey, I., \& Frankenberger, J. (2015). "Defining Soil and Water Assessment Tool (SWAT) hydrologic response units (HRUs) by field boundaries". International Journal of Agricultural and Biological Engineering, Vol 8(1),pp. 42-49.

Kuhn, C. (2014). "Modeling rainfall-runoff using SWAT in a small urban wetland". Yale University School of Forestry and Environmental Studies, pp. 1-19.

Marshall, E., \& Randhir, T. (2008). "Effect of climate change on watershed system: a regional analysis". Springer , 89, pp. 263-280.

Panhalkar, S. (2014). "Hydrological modeling using SWAT model and geoinformatic techniques". The Egyptian Journal of Remote Sensing and Space Sciences, 17, pp. 197-207

Renganathan, T., Silambarasan, A., Dopson, R. B., \& Shanmuga, A. A. (2015). "Hydrological Modelling of Poondi Sub-Watershed using ArcSWAT". International Journal of Advanced Remote Sensing and GIS, Volume 4, Issue 1, pp. 1323-1333.

Zahabiyoun, B., Goodarzi, M. R., Bavani, A. R., \& Azamathulla, H. M. (2013). Assessment of Climate Change Impact on the Gharesou River Basin Using SWAT Hydrological Model. Clean - Soil, Air, Water , 41, pp. 1-9.

https://www.climatehotmap.org/global-warming-

effects/food.html

https://climate.nasa.gov/

http://blogs.cornell.edu/sustainablewaterresourcemanagement/ 